\title{
ANALISIS COST VOLUME PROFIT UNTUK PERENCANAAN LABA PADA RESTORAN PRALINE \& OREGANO
}

\author{
Leviandi Adhie \\ Program Studi Akuntansi, Institut Manajemen Wiyata Indonesia Sukabumi Jawa Barat, \\ Indonesia \\ leviandi_adhie@gmail.com \\ Vinny Stefanie Sukmajaya \\ Program Studi Akuntansi, Institut Manajemen Wiyata Indonesia Sukabumi Jawa Barat, \\ Indonesia \\ vinnystefanie25@gmail.com
}

\begin{abstract}
This study aims to determine how the analysis of cost volume profit for profit planning Praline \& Oregano Restaurants. The research methodology used in this study is a descriptive study by analyzing the financial statements of Praline \& Oregano Restaurants with a time span of $2 Q$ 2017 - 1Q 2019 using cost volume profit analysis. The results found that the highest contribution margin occurred in the category Other drinks which included Dilmah, ice tea, and mineral water and Fussion Bite food categories which included Acapulco Tori, Paneer Dori With Kuah Padeh, Crispy Yakitori, and Yummy Tandoori. This study also found that the Break Even Point of Praline \& Oregano restaurants in each quarter from quarter 22017 to quarter 22019 was always achieved with a nominal range of Rp. 89,211,165 - Rp. 186,159,079 this happens because the sales generated are greater than the break-even sales. This study also found that the Margin Of Safety is known to experience a fluctuating increase in the ratio of $62-76 \%$ which indicates that the company always benefits. This study calculates Praline \& Oregano's profit target will get a profit of Rp. 274,925,768 in the 3rd quarter of 2019.
\end{abstract}

Keywords: Cost Volume Profit Analysis, Contribution Margin, Break Even Point, Margin of Safety, Profit Target

\section{PENDAHULUAN}

Laba merupakan salah satu tolak ukur kesuksesan manajemen dalam mengelola usahanya. Perusahan yang berorientasi pada laba tentu harus memiliki manajemen keuangan yang tanggap dalam perencanaan, pengendalian dan pengambilan keputusan mengenai perolehan laba dari penjualan. Perusahan yang berorientasi pada laba tentu harus memiliki manajemen keuangan yang tanggap dalam perencanaan, pengendalian dan pengambilan keputusan mengenai perolehan laba dari penjualan. Perusahaan harus mengetahui berapa banyak aktivitas penjualan yang harus dilakukan untuk bisa mendapatkan pendapatan agar memperoleh laba. Untuk membuat laba terus meningkat, perusahaan perlu membuat suatu perencanaan yang tepat dan cermat dalam menjalankan kegiatan operasionalnya. Untuk mengkaji hubungan antara laba, pendapatan, dan biaya bisa dikaji dengan analisis cost volume profit yang merupakan alat untuk menganalisis perencanaan laba yang dapat dipakai oleh manajemen sebagai teknik suatu perencanaan, pengendalian, serta pengambilan keputusan pada kegiatan perusahaan dalam mencapai laba dan menghadapi perubahan yang mungkin terjadi atas volume penjualan, harga jual serta biaya yang dikeluarkan (Wiyasha, 
2014). Dalam perhitungan dan pengimplementasian perencanaan laba menggunakan analisis cost volume profit, diharapkan dapat memberikan masukan pada perusahaan dalam membuat perencanaan yang lebih baik dan sistematis untuk mencapai laba yang optimal. Analisis cost volume profit dapat digunakan untuk mengetahui atau membuat peramalan laba penjualan. Penganalisisan cost volume profit tersebut dilakukan dengan menggunakan metode analisis contribution margin, analisis break even point, margin of safety, dan analisis target laba (Saparida, Marheni, \& Miranda, 2015).

Analisis cost volume profit ini dapat digunakan di industri penjualan makanan dan minuman untuk perencanaan labanya, dan bisa digunakan untuk merencanakan perencanaan laba untuk Restoran Praline \& Oregano. Jika Restoran Praline dan Oregano dalam perhitungan dan pengimplementasian perencanaan laba menggunakan analisis cost volume profit, diharapkan dapat membuat perencanaan yang sistematis untuk mencapai laba yang optimal. Maka dari itu penelitian ini bertujuan untuk mengetahui bagaimana analisis cost volume profit untuk perencanaan laba pada Restoran Praline \& Oregano.

\section{TINJAUAN PUSTAKA}

\section{A. Perencanaan Laba}

Perencanaan laba adalah analisis terhadap hasil selisih antara pendapatan dan biaya disuatu perusahaan yang diharapkan dapat menghasilkan keutungan yang disebut dengan laba. Perencanaan laba atau yang biasa di sebut dengan budget adalah pedoman atau petunjuk bagi setiap individu dalam suatu organisasi tentang bagaimana seharusnya individu tersebut bekerja untuk dapat mencapai sasaran perusahaan yang di harapkan sesuai dengan visi, misi, dan target yang dimiliki organisasi. Petunjuk ini biasanya berisi informasi dan data tentang suatu rencana kerja di masa datang bagi setiap departemen yang berada di dalam perusahaan. Budget ini merupakan rencana kerja yang digunakan untuk mencapai target penjualan dan untuk mengawasi penggunaan biaya. Kedua komponen penting budget tersebut dituangkan secara detail sebagai panduan kerja. Budget memiliki fungsi yaitu sebagai alat perencanaan, alat pengawasan dan alat penilaian kinerja (Munandar, 2000).

Konsep perencanaan laba yang besar dapat dicapai manajemen dengan menempuh langkah (Duyo, 2013):

1. Menekan biaya produksi maupun biaya operasi serendah mungkin dengan mempertahankan tingkat harga jual dan volume penjualan yang ada.

2. Menentukan harga jual sedemikian rupa sesuai dengan laba yang diinginkan.

3. Meningkatkan volume penjualan sebesar mungkin.

B. Analisis Cost Volume Profit (CVP)

Cost Volume Profit merupakan alat analisis manajemen untuk menentukan kinerja operasional jangka pendek. CVP mengkaji hubungan antara laba, volume, dan biaya yang terjadi dalam satu periode akuntansi. Kajian hubungan variable-variabel tersebut dapat memberikan informasi kepada manajemen untuk biaya-biaya yang terjadi serta volume yang harus dihasilkan untuk mencapai target laba 
tertentu. Dengan analisis CVP, manajer mendapat informasi seperti berapa penjualan yang harus terjual dengan tingkat harga tertentu agar perusahaan berada pada titik pulang pokok. Dengan informasi yang didapat ini manajemen memiliki informasi yang didapat ini manajemen memiliki informasi jika kinerja saat ini berapa pada titik ambang batas atau berada pada titik aman tertentu (Wiyasha, 2014).

\begin{tabular}{|c|c|}
\hline Ratio Contribution & Contribution Margin \\
\hline Margin $=$ & $\begin{array}{c}\text { Penjualan } \\
\end{array}$ \\
\hline
\end{tabular}

Teknik analisis CVP ini untuk menentukan berapa besar penjualan yang harus dihasilkan agar perusahaan berada pada posisi tidak rugi dan tidak untung. Dengan teknik analasis CVP ini manajemen dapat mengetahui perilaku biaya yang terjadi. Analisis perilaku biaya yang terjadi memberikan gambaran kepada manajemen mengenai proporsi biaya variabel dan biaya tetap. Analisis CVP memiliki elemen yaitu contribution margin, analisis break even point, margin of safety, dan analisis target laba.

C. Contribution Margin

Contribution margin merupakan selisih antara harga jual dengan biaya variabel setiap unit. Margin kontribusi menunjukkan jumlah yang tersedia menutup biaya variabel dan beban tetap yang kelebihannya merupakan laba (Wiyasha, 2014).

Contribution Margin merupakan pendapatan dari penjualan dikurangi dengan biaya variabel. Contribution margin menunjukkan jumlah yang tersedia menutup biaya variabel dan beban tetap yang kelebihannya merupakan laba. Semakin besar contribution margin maka semakin besar kesempatan yang di peroleh perusahaan untuk menutup biaya tetap dan untuk menghasilkan laba karena begitu pula sebaliknya, jika contribution margin yang diperoleh lebih kecil akan mengalami kerugian. Berikut rumus dan penghitungan contribution margin dan ratio contribution margin.

$$
\begin{array}{cl}
\text { Contribution } & \text { Penjulan - } \\
\text { Margin }= & \text { Biaya Variabel }
\end{array}
$$

\section{Break Even Point}

Break Even Point adalah suatu keadaan dimana perusahaan beroperasi dalam kondisi tidak memperoleh pendapatan (laba) dan tidak pula menderita kerugian. Artinya, dalam kondisi ini jumlah pendapatan yang diterima sama dengan jumlah biaya yang dikeluarkan. Lebih lanjut analisis ini digunakan untuk menetukan berapa unit yang harus dijual agar kita memperoleh keuntungan, baik dalam volume penjualan dalam unit maupun dalam rupiah (Kasmir, 2013).

Analisis Break Even Point adalah suatu cara atau teknik yang digunakan oleh seorang manajer perusahaan untuk mengetahui jumlah penjualan yang harus dia capai agar perusahaan berada pada keadaan suatu perusahaan yang pendapatan penjualannya sama dengan jumlah total biayanya. Analisis break even point pada penelitian ini menggunakan analisis break even point multi-product karena Praline dan Oregano menyediakan jenis menu yang beragam dengan harga yang berbeda dan jenis yang berbeda maka digunakan perhitungan break even point dalam rupiah. 
Berikut rumus perhitungan break even point.

$$
\text { Break Even Point }=\frac{\text { Fixed Cost }}{1-\frac{\text { Variabel Cost }}{\text { Sales }}}
$$

E. Margin Of Safety

Margin of safety adalah suatu informasi mengenai sampai tingkat berapa perusahaan boleh mengalami penurunan penjualan namun perusahaan tidak mengalami kerugian. Analisis margin of safety untuk menghitung jumlah dimana penjualan dapat menurun sebelum kerugian mulai terjadi. Semakin tinggi margin of safety maka semakin rendah risiko untuk tidak balik modal (Saparida et al., 2015).

Margin of safety merupakan hubungan atau selisih antara penjualan tertentu (sesuai anggaran) dengan penjualan pada titik impas. Margin Of Safety digunakan untuk mengatahui berapa besar penghasilan penjualan yang dianggarkan untuk mengantisipasi penurunan penjualan agar tidak mengalami kerugian (Kasmir, 2013) . Berikut rumus dan perhitungan margin of safety.

\begin{tabular}{|llc|}
\hline Margin & Total & Penjulan - \\
Safety $=$ & Total & Penjualan \\
& Impas
\end{tabular}

\begin{tabular}{|ll|}
\hline $\begin{array}{l}\text { Ratio } \\
\text { of }\end{array} \quad \begin{array}{l}\text { Margin } \\
\text { Safety }=\end{array}$ & $\frac{\text { Margin Of Safety }}{\text { Total Penjualan }} \times 1000$ \\
\hline
\end{tabular}

\section{F. Analisis Target Laba}

Dalam perhitungan titik impas target laba sama dengan nol, sedangkan dalam analisis target laba jumlah yang diperhitungkan dalam formulanya disesuaikan dengan jumlah laba yang diinginkan, biasanya lebih besar dari nol (Samryn, 2012).

$$
\text { Target Fix Cost }+ \text { Target lab }
$$$$
\text { Laba }=\overline{\text { Ratio Contribution } \mathrm{Ma}}
$$

\section{METODE PENELITIAN}

1. Jenis Penelitian

Penelitian ini merupakan penelitian deskriptif, yaitu penelitian yang dimaksudkan untuk memberikan informasi mengenai data yang diamati agar bermakna dan komunikatif, dilakukan dengan cara memecahkan permasalahan yang ada sekarang kemudian memprediksi keadaan di masa yang akan datang (Purwanto, 2010). Penelitian ini dimaksudkan untuk menjelaskan bagaimana menyusun perencanaan laba dengan melakukan pengumpulan data-data yang kemudian diolah dengan menggunakan analisis cost volume profit dengan metode contribution margin, break even point, margin of safety, dan analisis target laba yang digunakan sebagai alat bantu untuk perencanaan laba.

2. Lokasi Dan Waktu Penelitian

Dalam menyelesaikan penelitian ini dilakukan di Restoran Praline dan Oregano yang berlokasi di Kota Sukabumi. Penelitian ini dilakukan pada bulan September 2018 - Agustus 2019.

3. Metode Analisis Data

Metode analisis data dilaksanakan dengan melakukan perhitunganperhitungan yang relevan terhadap masalah yang diteliti yaitu perencanaan laba dengan menggunakan bantuan program Microsoft Excel 2010. Data 
yang digunakan adalah laporan laba rugi Restoran Praline \& Oregano Juli 2016 Maret 2019. Untuk menentukan laba yang direncanakan digunakan analisis cost volume profit dengan contribution margin, analisis break event point, margin of safety dan analisis target laba.

\section{Hasil Pembahasan}

Data yang diperlukan dalam penelitian ini yaitu data sekunder yang berupa data pendapatan dan biaya Praline \& Oregano selama dua tahun, yaitu dari quartal 22017 - quartal 1 2019. Laba yang diterima Praline \& Oregano merupakan hasil dari penjualan makanan dan minuman dikurangi dengan biaya yang dikeluarkan. Disini, penulis mengklasifikasikan biaya menjadi biaya tetap dan biaya variable. Berikut data penjualan dan biaya makanan dan minuman Praline \& Oregano Quartal 2 2017 - Quartal 12019.

\section{Tabel 1}

Data Penjualan dan Biaya Restoran Praline \& Oregano Quartal 22017 - Quartal 12019

\begin{tabular}{|c|c|c|c|c|}
\hline $\begin{array}{l}\text { Keter } \\
\text { angan }\end{array}$ & Sales & $\begin{array}{c}\text { Variabel } \\
\text { Cost }\end{array}$ & $\begin{array}{l}\text { Fix } \\
\text { Cost }\end{array}$ & $\begin{array}{c}\text { Reven } \\
\text { ue }\end{array}$ \\
\hline $\begin{array}{l}\text { Quarta } \\
12 \\
2017\end{array}$ & $\begin{array}{l}336,34 \\
0,575\end{array}$ & $\begin{array}{l}138,829,9 \\
23\end{array}$ & $\begin{array}{l}74,65 \\
2,085\end{array}$ & $\begin{array}{l}122,85 \\
8,567\end{array}$ \\
\hline $\begin{array}{l}\text { Quarta } \\
13 \\
2017\end{array}$ & $\begin{array}{l}349,43 \\
5,055\end{array}$ & $\begin{array}{l}215,635,2 \\
29\end{array}$ & $\begin{array}{l}71,28 \\
0,921\end{array}$ & $\begin{array}{l}62,518 \\
906\end{array}$ \\
\hline $\begin{array}{l}\text { Quarta } \\
14 \\
2017\end{array}$ & $\begin{array}{l}304,51 \\
3,075\end{array}$ & $\begin{array}{l}157,137,6 \\
72\end{array}$ & $\begin{array}{l}43,17 \\
5,589 \\
\end{array}$ & $\begin{array}{l}104,19 \\
9,814 \\
\end{array}$ \\
\hline $\begin{array}{l}\text { Quarta } \\
11 \\
2018\end{array}$ & $\begin{array}{l}349,23 \\
0,281 \\
\end{array}$ & $\begin{array}{l}157,333,2 \\
01\end{array}$ & $\begin{array}{l}59,64 \\
2,146 \\
\end{array}$ & $\begin{array}{l}132,25 \\
4,934\end{array}$ \\
\hline $\begin{array}{l}\text { Quarta } \\
12 \\
2018 \\
\end{array}$ & $\begin{array}{l}395,74 \\
6,677\end{array}$ & $\begin{array}{l}159,766,6 \\
08\end{array}$ & $\begin{array}{l}55,90 \\
4,680 \\
\end{array}$ & $\begin{array}{l}180,07 \\
5,389\end{array}$ \\
\hline $\begin{array}{l}\text { Quarta } \\
13 \\
2018 \\
\end{array}$ & $\begin{array}{l}400,49 \\
1,423 \\
\end{array}$ & $\begin{array}{l}162,126,7 \\
46\end{array}$ & $\begin{array}{l}74,52 \\
7,854 \\
\end{array}$ & $\begin{array}{l}163,83 \\
6,823 \\
\end{array}$ \\
\hline $\begin{array}{l}\text { Quarta } \\
14 \\
2018\end{array}$ & $\begin{array}{l}397,40 \\
5,099\end{array}$ & $\begin{array}{l}158,686,5 \\
62\end{array}$ & $\begin{array}{l}64,81 \\
5,362 \\
\end{array}$ & $\begin{array}{l}173,90 \\
3,175\end{array}$ \\
\hline $\begin{array}{l}\text { Quarta } \\
11 \\
2019 \\
\end{array}$ & $\begin{array}{l}378,54 \\
2,116 \\
\end{array}$ & $\begin{array}{l}132,998,3 \\
70 \\
\end{array}$ & $\begin{array}{l}63,17 \\
0,652 \\
\end{array}$ & $\begin{array}{l}182,37 \\
3,094 \\
\end{array}$ \\
\hline
\end{tabular}

\section{Contribution Margin}

Contribution margin merupakan penghasilan penjualan dikurangi dengan biaya variabel. Semakin besar contribution margin maka semakin besar kesempatan yang di peroleh perusahaan untuk menutup biaya tetap dan untuk menghasilkan laba karena begitu pula sebaliknya, jika contribution margin yang diperoleh lebih kecil akan mengalami kerugian. Berikut perhitungan contribution margin Praline \& Oregano Quartal 22017 - Quartal 1 2019.

Tabel 2

Contribution Margin Praline \& Oregano Quartal 22017 - Quartal 12019

\begin{tabular}{|c|c|c|c|c|c|}
\hline \multicolumn{6}{|c|}{ Contribution Margin } \\
\hline $\begin{array}{l}\text { Keter } \\
\text { angan }\end{array}$ & Sales & $\begin{array}{l}\text { Variab } \\
\text { el Cost }\end{array}$ & $\begin{array}{c}\text { Contribution } \\
\text { Margin }\end{array}$ & $\begin{array}{l}R \\
a t i \\
o \\
\end{array}$ & $\begin{array}{c}\text { Peru } \\
\text { baha } \\
\text { n }\end{array}$ \\
\hline $\begin{array}{l}\text { Quarta } \\
12 \\
2017\end{array}$ & $\begin{array}{l}336,34 \\
0,575\end{array}$ & $\begin{array}{l}138,82 \\
9,923\end{array}$ & $197,510,652$ & $\begin{array}{l}59 \\
\%\end{array}$ & - \\
\hline $\begin{array}{l}\text { Quarta } \\
13 \\
2017\end{array}$ & $\begin{array}{l}349,43 \\
5,055 \\
\end{array}$ & $\begin{array}{l}215,63 \\
5,229 \\
\end{array}$ & $133,799,826$ & $\begin{array}{r}38 \\
\%\end{array}$ & $-20 \%$ \\
\hline $\begin{array}{l}\text { Quarta } \\
14 \\
2017\end{array}$ & $\begin{array}{l}304,51 \\
3,075 \\
\end{array}$ & $\begin{array}{l}157,13 \\
7,672 \\
\end{array}$ & $147,375,403$ & $\begin{array}{r}48 \\
\%\end{array}$ & $10 \%$ \\
\hline $\begin{array}{l}\text { Quarta } \\
11 \\
2018\end{array}$ & $\begin{array}{l}349,23 \\
0,281 \\
\end{array}$ & $\begin{array}{l}157,33 \\
3,201 \\
\end{array}$ & $191,897,080$ & $\begin{array}{r}55 \\
\%\end{array}$ & $7 \%$ \\
\hline $\begin{array}{l}\text { Quarta } \\
12 \\
2018\end{array}$ & $\begin{array}{l}395,74 \\
6,677\end{array}$ & $\begin{array}{l}159,76 \\
6,608\end{array}$ & $235,980,069$ & $\begin{array}{r}60 \\
\%\end{array}$ & $5 \%$ \\
\hline $\begin{array}{l}\text { Quarta } \\
13 \\
2018\end{array}$ & $\begin{array}{l}400,49 \\
1,423\end{array}$ & $\begin{array}{l}162,12 \\
6,746\end{array}$ & $238,364,677$ & $\begin{array}{r}60 \\
\%\end{array}$ & - \\
\hline $\begin{array}{l}\text { Quarta } \\
14 \\
2018\end{array}$ & $\begin{array}{l}397,40 \\
5,099\end{array}$ & $\begin{array}{l}158,68 \\
6,562 \\
\end{array}$ & $238,718,537$ & $\begin{array}{r}60 \\
\%\end{array}$ & - \\
\hline $\begin{array}{l}\text { Quarta } \\
11 \\
2019\end{array}$ & $\begin{array}{l}378,54 \\
2,116\end{array}$ & $\begin{array}{l}132,99 \\
8,370\end{array}$ & $245,543,746$ & $\begin{array}{r}65 \\
\%\end{array}$ & - \\
\hline
\end{tabular}

Dari data tabel 2 dapat diketahui bahwa Praline \& Oregano dari quartal 2 2017 - quartal 12019 cenderung meningkat walaupun fluktuatif. Hasil perhitungan ratio contribution margin akan menunjukan pendapatan yang diperoleh Praline \& Oregano untuk menutupi biaya tetap. Dengan demikian 
contribution margin ini digunakan untuk mengetahui efisiensi perusahaan dengan melihat kepada besar kecilnya laba kontribusi dalam hubungannya dengan penjualan. Untuk melihat contribution margin berdasarkan Kategori produk makanan dan minuman pada menu Praline dan Oregano, berikut adalah hasil perhitungan contribution margin dan ratio contribution margin pada masingmasing kategori produk.

Tabel 3

Contribution Margin per Kategori Menu Praline \& Oregano

\begin{tabular}{|c|c|c|c|c|c|}
\hline No & Kategori & $\begin{array}{c}\text { Harga } \\
\text { Jual }\end{array}$ & $\begin{array}{c}\text { Biaya } \\
\text { Variabel }\end{array}$ & $\begin{array}{c}\text { CM per } \\
\text { unit }\end{array}$ & $\begin{array}{c}\text { Ratio } \\
\text { CM }\end{array}$ \\
\hline 1 & Based & 30,000 & 5,739 & 24,261 & $81 \%$ \\
\hline 2 & Creamy & 42,000 & 8,765 & 33,235 & $79 \%$ \\
\hline 3 & Flavour & 32,000 & 6,400 & 25,600 & $80 \%$ \\
\hline 4 & Brew & 30,000 & 5,739 & 24,261 & $81 \%$ \\
\hline 5 & Margarita & 40,000 & 8,000 & 32,000 & $80 \%$ \\
\hline 6 & Mixologis & 30,000 & 9,391 & 20,609 & $69 \%$ \\
\hline 7 & Mojito & 42,000 & 8,035 & 33,965 & $81 \%$ \\
\hline 8 & Other & 20,000 & 3,130 & 16,870 & $84 \%$ \\
\hline 9 & Fraffe & 42,000 & 8,400 & 33,600 & $80 \%$ \\
\hline 10 & Salad & 45,000 & 12,522 & 32,478 & $72 \%$ \\
\hline 11 & Soup & 38,000 & 10,574 & 27,426 & $72 \%$ \\
\hline 12 & Bites A & 28,000 & 7,304 & 20,696 & $74 \%$ \\
\hline 13 & Bites B & 60,000 & 12,939 & 47,061 & $78 \%$ \\
\hline 14 & Pizza A & 58,000 & 17,217 & 40,783 & $70 \%$ \\
\hline 16 & Pasta & 55,000 & 16,644 & 38,356 & $70 \%$ \\
\hline 17 & Main & 68,000 & 19,513 & 48,487 & $71 \%$ \\
\hline 18 & Grill A & 70,000 & 16,696 & 53,304 & $76 \%$ \\
\hline 19 & Grill B & 118,000 & 35,913 & 82,087 & $70 \%$ \\
\hline 20 & Grill C & 180,000 & 59,478 & 120,522 & $67 \%$ \\
\hline 21 & Fussion & 72,000 & 14,626 & 57,374 & $80 \%$ \\
\hline 22 & Combo & 150,000 & 45,652 & 104,348 & $70 \%$ \\
\hline 23 & $\begin{array}{l}\text { Asian } \\
\text { Rice }\end{array}$ & 58,000 & 21,287 & 36,713 & $63 \%$ \\
\hline 24 & Bento A & 58,000 & 18,357 & 39,643 & $68 \%$ \\
\hline 25 & Bento B & 80,000 & 22,485 & 57,515 & $72 \%$ \\
\hline 26 & Healthy & 68,000 & 19,217 & 48,783 & $72 \%$ \\
\hline 27 & Sandwich & 58,000 & 14,122 & 43,878 & $76 \%$ \\
\hline 28 & Cookies & 75,000 & 21,569 & 53,431 & $71 \%$ \\
\hline 29 & Cake & 350,000 & 118,696 & 231,304 & $66 \%$ \\
\hline
\end{tabular}

Pada tabel 3 dapat terlihat bahwa di Praline dan Oregano untuk menu minuman pada kategori Other memberikan contribution margin paling tinggi yaitu $84 \%$ dengan harga jual per porsi Rp. 20.000 dan contribution margin per porsi Rp. 16.870. Kategori mixologis memberikan contribution margin paling rendah yaitu $69 \%$ dengan harga jual per porsi Rp. 30.000 dan contribution margin per porsi Rp.
20.609. Untuk menu makanan pada kategori Fussion memberikan contribution margin paling tinggi yaitu $80 \%$ dengan harga jual per porsi Rp. 72.000 dan contribution margin per porsi Rp. 57.374. Kategori Asian Rice yang memberikan contribution margin rendah yaitu $63 \%$ dengan harga jual per porsi Rp. 58.000 dan contribution margin per porsi Rp. 36.713.

2. Break Even Point

Break Even Point akan menunjukan suatu keadaan dimana dalam operasional kegiatan penjualan Praline \& Oregano dalam keadaan tidak memperoleh laba dan tidak memperoleh kerugian. Berikut perhitungan Break Even Point Praline \& Oregano Quartal 2 2017 - Quartal 12019.

Tabel 4

Break Even Point Praline \& Oregano Quartal 2 2017 - Quartal 12019

\begin{tabular}{|c|c|c|c|c|c|}
\hline \multicolumn{6}{|c|}{ Break Even Point } \\
\hline $\begin{array}{l}\text { Keter } \\
\text { angan }\end{array}$ & $\begin{array}{c}\text { Fixe } \\
d \\
\text { Cost }\end{array}$ & $\begin{array}{l}\text { Variab } \\
\text { el Cost }\end{array}$ & Sales & $\begin{array}{c}\text { Break } \\
\text { Even } \\
\text { Point }\end{array}$ & $\begin{array}{c}\text { Perub } \\
\text { ahan }\end{array}$ \\
\hline $\begin{array}{l}\text { Quart } \\
\text { al } 2 \\
2017\end{array}$ & $\begin{array}{l}74,65 \\
2,085\end{array}$ & $\begin{array}{l}138,82 \\
9,923\end{array}$ & $\begin{array}{l}336,3 \\
40,57 \\
5\end{array}$ & $\begin{array}{l}127,124, \\
917\end{array}$ & - \\
\hline $\begin{array}{l}\text { Quart } \\
\text { al } 3 \\
2017\end{array}$ & $\begin{array}{l}71,28 \\
0,921\end{array}$ & $\begin{array}{l}215,63 \\
5,229\end{array}$ & $\begin{array}{l}349,4 \\
35,05 \\
5\end{array}$ & $\begin{array}{l}186,159, \\
079\end{array}$ & $\begin{array}{c}59,034, \\
162\end{array}$ \\
\hline $\begin{array}{l}\text { Quart } \\
\text { al } 4 \\
2017\end{array}$ & $\begin{array}{l}43,17 \\
5,589\end{array}$ & $\begin{array}{l}157,13 \\
7,672\end{array}$ & $\begin{array}{l}304,5 \\
13,07 \\
5 \\
\end{array}$ & $\begin{array}{l}89,211,1 \\
65\end{array}$ & $\begin{array}{l}(96,94 \\
7,914)\end{array}$ \\
\hline $\begin{array}{l}\text { Quart } \\
\text { al } 1 \\
2018\end{array}$ & $\begin{array}{l}59,64 \\
2,146\end{array}$ & $\begin{array}{l}157,33 \\
3,201\end{array}$ & $\begin{array}{l}349,2 \\
30,28 \\
1\end{array}$ & $\begin{array}{l}108,541, \\
742\end{array}$ & $\begin{array}{c}19,330 \\
578\end{array}$ \\
\hline $\begin{array}{l}\text { Quart } \\
\text { al } 2 \\
2018\end{array}$ & $\begin{array}{l}55,90 \\
4,680\end{array}$ & $\begin{array}{l}159,76 \\
6,608\end{array}$ & $\begin{array}{l}395,7 \\
46,67 \\
7\end{array}$ & $\begin{array}{l}93,754,0 \\
68\end{array}$ & $\begin{array}{l}(14,78 \\
7,675)\end{array}$ \\
\hline $\begin{array}{l}\text { Quart } \\
\text { al } 3 \\
2018\end{array}$ & $\begin{array}{l}74,52 \\
7,854\end{array}$ & $\begin{array}{l}162,12 \\
6,746\end{array}$ & $\begin{array}{l}400,4 \\
91,42 \\
3 \\
\end{array}$ & $\begin{array}{l}125,218, \\
915\end{array}$ & $\begin{array}{c}31,464 \\
848\end{array}$ \\
\hline $\begin{array}{l}\text { Quart } \\
\text { al } 4 \\
2018\end{array}$ & $\begin{array}{l}64,81 \\
5,362\end{array}$ & $\begin{array}{l}158,68 \\
6,562\end{array}$ & $\begin{array}{l}397,4 \\
05,09 \\
9\end{array}$ & $\begin{array}{l}107,900, \\
943\end{array}$ & $\begin{array}{l}(17,31 \\
7,972)\end{array}$ \\
\hline $\begin{array}{l}\text { Quart } \\
\text { al } 1 \\
2019\end{array}$ & $\begin{array}{l}63,17 \\
0,652\end{array}$ & $\begin{array}{l}132,99 \\
8,370\end{array}$ & $\begin{array}{l}378,5 \\
42,11 \\
6\end{array}$ & $\begin{array}{l}97,386,9 \\
33\end{array}$ & $\begin{array}{l}(10,51 \\
4,011)\end{array}$ \\
\hline
\end{tabular}

Dapat diketahui pada tabel 4 bahwa Break Even Point Praline \& 
Oregano pada tiap quartal dari quartal 2 2017 - quartal 12019 selalu dicapai karena penjualan yang dihasilkan lebih besar dari penjualan impas. Tetapi adanya fluktuatif dalam break even point Praline \& Oregano dari quartal 22017 quartal 12019 yang disebabkan karena 2 faktor, yaitu penjualan yang lebih besar atau kecil dan biaya yang lebih besar atau kecil.

\section{Margin Of Safety}

Margin Of Safety digunakan untuk mengatahui berapa besar penghasilan penjualan yang dianggarkan untuk mengantisipasi penurunan penjualan agar tidak mengalami kerugian dan mengetahui kesempatan untuk mendapatkan laba. Berikut perhitungan Margin of Safety Praline \& Oregano Quartal 22017 - Quartal 1 2019.

Tabel 5

Margin Of Safety Praline \& Oregano Quartal 22017 - Quartal 12019

\begin{tabular}{|c|c|c|c|c|c|}
\hline \multicolumn{6}{|c|}{ Margin Of Safety } \\
\hline $\begin{array}{l}\text { Keter } \\
\text { angan }\end{array}$ & Sales & $\begin{array}{c}\text { Break } \\
\text { Even } \\
\text { Point }\end{array}$ & $\begin{array}{c}\text { Margin } O f \\
\text { Safety }\end{array}$ & $\begin{array}{l}R \\
a t \\
\text { io } \\
\end{array}$ & $\begin{array}{c}\text { Peru } \\
\text { baha } \\
\text { n } \\
\end{array}$ \\
\hline $\begin{array}{l}\text { Quart } \\
\text { al } 2 \\
2017\end{array}$ & $\begin{array}{l}336,3 \\
40,57 \\
5\end{array}$ & $\begin{array}{l}127,124, \\
917\end{array}$ & $\begin{array}{l}209,215,65 \\
8\end{array}$ & $\begin{array}{r}62 \\
\%\end{array}$ & - \\
\hline $\begin{array}{l}\text { Quart } \\
\text { al } 3 \\
2017\end{array}$ & $\begin{array}{l}349,4 \\
35,05 \\
5\end{array}$ & $\begin{array}{l}186,159, \\
079\end{array}$ & $\begin{array}{l}163,275,97 \\
6\end{array}$ & $\begin{array}{r}47 \\
\%\end{array}$ & $15 \%$ \\
\hline $\begin{array}{l}\text { Quart } \\
\text { al } 4 \\
2017\end{array}$ & $\begin{array}{l}304,5 \\
13,07 \\
5\end{array}$ & $\begin{array}{l}89,211,1 \\
65\end{array}$ & $\begin{array}{l}215,301,91 \\
0\end{array}$ & $\begin{array}{l}71 \\
\%\end{array}$ & $24 \%$ \\
\hline $\begin{array}{l}\text { Quart } \\
\text { al } 1 \\
2018\end{array}$ & $\begin{array}{l}349,2 \\
30,28 \\
1 \\
\end{array}$ & $\begin{array}{l}108,541, \\
742\end{array}$ & $\begin{array}{l}240,688,53 \\
9\end{array}$ & $\begin{array}{r}69 \\
\%\end{array}$ & $-2 \%$ \\
\hline $\begin{array}{l}\text { Quart } \\
\text { al } 2 \\
2018\end{array}$ & $\begin{array}{l}395,7 \\
46,67 \\
7 \\
\end{array}$ & $\begin{array}{l}93,754,0 \\
68\end{array}$ & $\begin{array}{l}301,992,60 \\
9\end{array}$ & $\begin{array}{r}76 \\
\%\end{array}$ & $7 \%$ \\
\hline $\begin{array}{l}\text { Quart } \\
\text { al } 3 \\
2018\end{array}$ & $\begin{array}{l}400,4 \\
91,42 \\
3 \\
\end{array}$ & $\begin{array}{l}125,218, \\
915\end{array}$ & $\begin{array}{l}275,272,50 \\
8\end{array}$ & $\begin{array}{r}69 \\
\%\end{array}$ & $-8 \%$ \\
\hline $\begin{array}{l}\text { Quart } \\
\text { al } 4 \\
2018\end{array}$ & $\begin{array}{l}397,4 \\
05,09 \\
9 \\
\end{array}$ & $\begin{array}{l}107,900, \\
943\end{array}$ & $\begin{array}{l}289,504,15 \\
6\end{array}$ & $\begin{array}{l}73 \\
\%\end{array}$ & $4 \%$ \\
\hline $\begin{array}{l}\text { Quart } \\
\text { al } 1 \\
2019\end{array}$ & $\begin{array}{l}378,5 \\
42,11 \\
6\end{array}$ & $\begin{array}{l}97,386,9 \\
33\end{array}$ & $\begin{array}{l}281,155,18 \\
3\end{array}$ & $\begin{array}{r}74 \\
\%\end{array}$ & $1 \%$ \\
\hline
\end{tabular}

Semakin besar tingkat margin of safety perusahaan semakin baik karena manandakan bahwa perusahaan dapat memperoleh laba yang semakin besar. Hal ini dikarenakan rentang penurunan penjualan yang diperbolehkan lebih besar sehingga kemungkinan menderita kerugian rendah. Pada tabel 5 terlihat bahwa margin of safety Praline dan Oregano dari quartal 22017 - 12019 cenderung mengalami peningkatan walaupun dalam perjalanannya fluktuatif. Dengan menggunakan metode margin of safety ini, akan berguna untuk Praline \& Oregano dalam menjaga agar penjualan tidak mengalami penurunan dari rasio margin of safety. Hal ini menunjukkan bahwa Praline \& Oregano mempunyai kesempatan untuk memperoleh laba yang besar karena Praline \& Oregano memiliki persentase margin of safety yang cukup besar dan cenderung meningkat dari quartal 22017 - quartal 12019 yang berarti bahwa semakin besar margin of safety maka semakin besar Praline \& Oregano kesempatan untuk memperoleh laba.

4. Analisis Target Laba

Praline \& Oregano memiliki target laba yaitu $67,5 \%$ dari hasil penjualan. Jika pada target penjualan Praline \& Oregano untuk quartal selanjutnya sebesar Rp. 600.000.000 dengan menggunakan biaya tetap yang sama dengan quartal sebelumnya, dan contribution margin quartal sebelumnnya maka akan didapat laba yang diinginkan pada quartal 32019 . Berikut perhitungan target laba Praline \& Oregano.

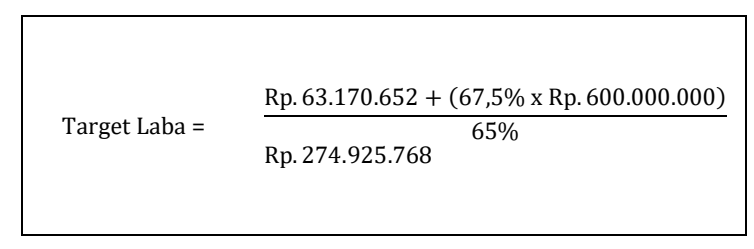

Dari hasil perhitungan tersebut dapat diketahui bahwa jika Praline \& Oregano mengharapkan penjualan 
perquartal sebesar Rp. 600.000 .000 dengan mendapatkan laba sebesar $67,5 \%$ dan menggunakan biaya tetap dan rasio kontribusi marjin dengan menggunakan data pada quartal 12019 yaitu Rp. 63.170 .652 biaya tetap dan $65 \%$ rasio kontributsi marjin akan diperoleh laba sebesar Rp. 274.925.768 pada quartal 3 2019.

\section{Kesimpulan}

Berdasarkan hasil analisis dan pembahasan maka dapat diambil simpulan sebagai berikut:

1. Berdasarkan analisis Contribution Margin Praline \& Oregano pada quartal 22017 - quartal 12019 cenderung meningkat walaupun fluktuatif. Hasil perhitungan ratio contribution margin akan menunjukan pendapatan yang diperoleh Praline \& Oregano untuk menutupi biaya tetap. Dan kontribusi laba terbesar yaitu dari Menu Minuman dengan kategori Other dan Menu Makanan dari kategori Fussion.

2. Berdasarkan analisis Break Even Point Praline \& Oregano Departemen Food \& Beverage Anugrah Hotel Sukabumi pada tiap quartal dari quartal 22017 - quartal 12019 selalu dicapai karena penjualan yang dihasilkan lebih besar dari penjualan impas.

3. Berdasarkan analisis Margin of safety Praline dan Oregano Departemen Food \& Beverage Anugrah Hotel Sukabumi dari quartal 22017 - 12019 cenderung mengalami peningkatan walaupun dalam perjalanannya fluktuatif dengan rentang 47-76\% hal ini dikarenakan adanya penurunan dan peningkatan pada penjualan dan break even point. Terjadi peningkatan Margin Of Safety yang mengindikasi bahwa perusahaan bertumbuh.

4. Berdasarkan perhitungan target laba untuk perencanaan laba jika Praline \& Oregano mengharapkan penjualan perquartal sebesar Rp. 600.000 .000 dengan mendapatkan laba sebesar $67,5 \%$ dan menggunakan biaya tetap dan rasio kontribusi marjin dengan menggunakan data pada quartal 12019 yaitu Rp. 63.170 .652 biaya tetap dan $65 \%$ rasio kontributsi marjin akan diperoleh laba sebesar Rp. 274.925 .768 pada quartal 3 2019.

\section{DAFTAR PUSTAKA}

Duyo, Sheila F. (2013). Analisis Cost Volume Profit Untuk Perencanaan Laba Pada Hotel Sintesa Peninsula Manado. Jurnal EMBA: Jurnal Riset Ekonomi, Manajemen, Bisnis Dan Akuntansi, 1(3).

Kasmir. (2013). Analisis Laporan Keuangan. Jakarta: PT. Raja Grafindo Persada.

Munandar, Mohammad. (2000). Budgeting: Perencanaan Kerja, Pengkoordinasian Kerja, Pengawasan Kerja.

Purwanto, M. Pd. (2010). Metodologi penelitian kuantitatif untuk psikologi dan pendidikan. Yogyakarta: Pustaka Pelajar.

Samryn, L. M. (2012). Akuntansi manajemen informasi biaya untuk mengendalikan aktivitas operasi dan investasi. In Edisi Pertama. Jakarta: Kencana Prenada Media Group.

Saparida, Satriani, Marheni, Marheni, \& Miranda, Lona. (2015). Analisis CostVolume-Profit Sebagai Alat Perencanaan Laba Jangka Pendek Pada Cv. Mentari Dempo Indah Pangkalpinang (Studi Kasus Pada CV. Mentari Dempo Indah, Pangkalpinang). Jurnal Akuntansi Bisnis \& Keuangan, 3(2), 28-51.

Wiyasha, I. B. M. (2014). Akuntansi Manajemen untuk HOTEL dan RESTORAN. 